\title{
Correction to: Measuring Histone Modifications in the Human Parasite Schistosoma mansoni
}

\section{Ronaldo de Carvalho Augusto, David Roquis, Marion AL Picard, Cristian Chaparro, Celine Cosseau, and Christoph Grunau}

Correction to:

Chapter 9 in: David J. Timson (ed.), Schistosoma mansoni: Methods and Protocols, Methods in Molecular Biology, vol. 2151, https://doi.org/10.1007/978-1-0716-0635-3_9

The affiliation of Dr. Ronaldo de Carvalho Augusto has been changed to LBMC, Laboratoire de Biologie et Modélisation de la Cellule Univ Lyon, ENS de Lyon, Université Claude Bernard Lyon 1, CNRS, UMR 5239, INSERM, U1210, Lyon, France.

The updated online version of this chapter can be found at: https://doi.org/10.1007/978-1-0716-0635-3_9 